\title{
LETTER
}

\section{Real-time ultrasound-guided percutaneous dilatational tracheostomy}

\author{
Shalim J Rodríguez* and Luis E Esteves \\ See related research by Rajajee et al., http://ccforum.com/content/15/1/R67
}

We read with interest the study conducted by Dr Rajajee and colleagues [1] and we do support the potential of ultrasound in the critical care setting [2].

We have observed that the best way to visualize artificial airways is with a longitudinal image of the trachea (Figure 1). Transversal images allow one to visualize the tube, but do not give certainty about its position when removed. In a longitudinal image, one can visualize a double line for the whole extension of the tube, enabling recognition of the distal tip [3]. When removing the tube, we visualize the process because of the unique line with increased echogenicity of the posterior surface of the trachea, which is well recognized if the space between the tracheal rings is free. Removal of the endotracheal tube might be insufficient using the laryngoscope, particularly in patients with short necks. Once the guidewire is in place, it can be visualized and followed with ultrasound (Figure 2). The guidewire is shown in the transversal image and in the longitudinal image, as it passes among the tracheal rings. The guidewire is observed in the airway by following it with ultrasound of the skin.

Ultrasound techniques should be used routinely to evaluate anterior structures of the neck, regardless of the guide used. The ability to visualize the path of the needle allows one to perform the procedure without incision. Additionally, the bronchofiberoscopic guide allows one to recognize intratracheal complications [4].

\section{Competing interests}

The authors declare that they have no competing interests.

Published: 19 September 2011

\section{References}

1. Rajajee V, Fletcher J, Rochlen L, Jacobs TL: Real-time ultrasound-guided percutaneous dilatational tracheostomy: a feasibility study. Crit Care 2011, 15:R67.

\footnotetext{
*Correspondence: shalimrodriguez@yahoo.es

Servicio de Cuidados Intensivos $1\left(2^{\circ} \mathrm{C}\right)$, Departamento de Cuidados Intensivos, Hospital Nacional Edgardo Rebagliati Martins - ESSALUD, Av. Rebagliati s/n, Jesus Maria, Lima 11, Lima, Perú
}

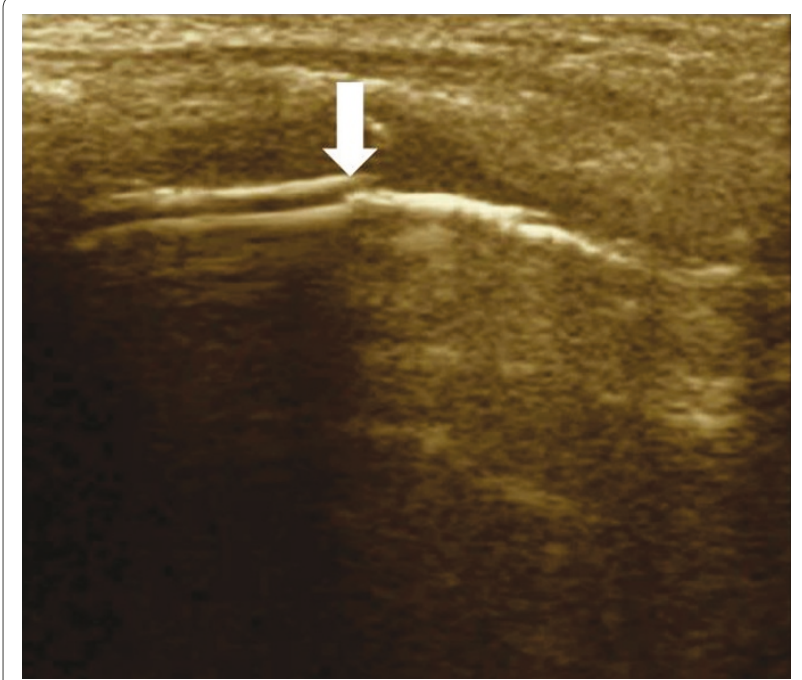

Figure 1. Removal of the orotracheal tube visualized in a longitudinal image. The tube is recognized as a double line (white arrow), leaving a single line that corresponds to the trachea. Author's image.

2. Adrienne R, Cook D: Ultrasound guidance for placement of central venous catheters: a meta analysis of the literature. Crit Care Med 1996, 24:2053-2058.

3. Galicinao J, Bush A, Godambe S: Use of bedside ultrasonography for endotracheal tube placement in pediatric patients: a feasibility study. Pediatrics 2007, 120:1297-1303.

4. Bertram S, Emshoff R, Norer B: Ultrasonographic anatomy of the anterior neck: implications for tracheostomy. J Oral Maxillofac Surg 1995, 53:1420-1424. 

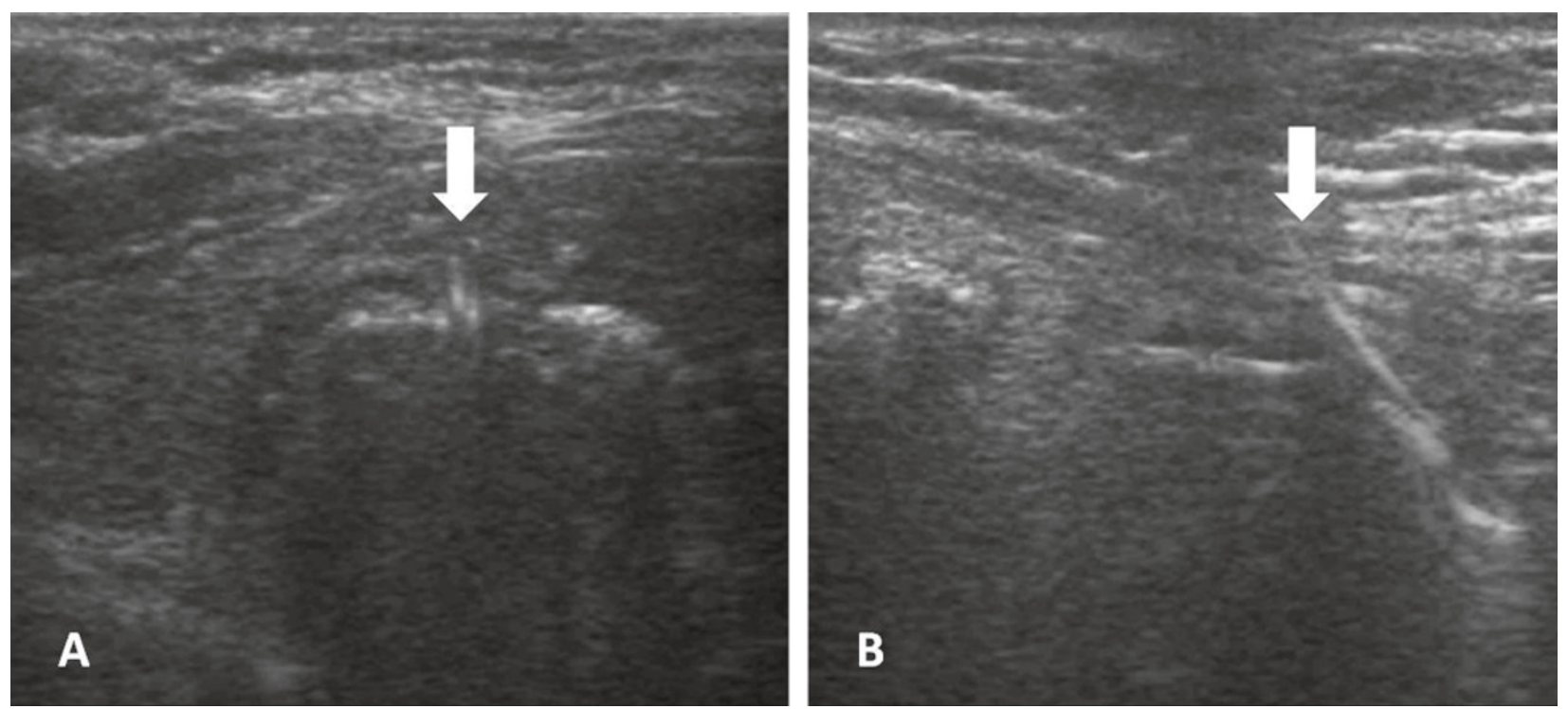

Figure 2. Verification of the guidewire in the airway. (A) Transversal image of the guidewire (white arrow) passing through the anterior wall of the trachea. (B) Longitudinal image of the guidewire (white arrow) passing below the second tracheal ring. Author's images. 